\title{
VM-26 in colorectal carcinoma: A Southwest Oncology Group Study
}

\author{
Noboru Oishi ${ }^{1}$, Thomas R. Fleming ${ }^{2}$, Leslie Laufman ${ }^{3}$, James S. Ungerleider ${ }^{4}$, Ronald B. Natale ${ }^{5}$, \\ Albert B. Einstein $\mathrm{Jr}^{6}{ }^{6}$, Daniel D. Von $\mathrm{Hoff}^{7}$ and John S. Macdonald ${ }^{8}$ \\ ${ }^{1}$ Cancer Research Center of Hawaii; ${ }^{2}$ Southwest Oncology Group Statistical Center - Seattle; ${ }^{3}$ Columbus \\ CCOP; ${ }^{4}$ Dayton CCOP; ${ }^{5}$ University of Michigan Medical Center; ${ }^{6}$ Virginia Mason CCOP; 7 University of \\ Texas Health Sciences Center - San Antonio; ${ }^{8}$ University of Kentucky Medical Center, USA
}

Key words: VM-26, chemotherapy, advanced colorectal cancer

\section{Summary}

In this multi-institutional phase II study, VM-26 or Teniposide was administered to forty-two patients with advanced colorectal cancer. Patients were initially treated at $60 \mathrm{mg} / \mathrm{M}^{2}$ daily for 5 days with dose adjustments depending on toxicity. One complete response and one partial response were observed lasting six and four months respectively. Leukopenia was severe in $40 \%$ of patients. No drug related deaths were seen. In this Southwest Oncology Group (SWOG) study, VM-26 appeared to have minimal benefit in advanced colorectal cancer.

\section{Introduction}

VM-26 or Teniposide is a derivative of the root of mandrake (Podophyllum peltatum). Wampler [1] reported $7 / 25(28 \%)$ response in advanced colorectal cancer treated with 5-FU and VM-26 with a median survival of $37+$ weeks. Woods [2] treated small cell carcinoma of the lung with daily $\times 5$ schedules with tolerable toxicity. In this Phase II study, daily $\times 5$ schedule has been instituted to determine its efficacy and toxicity in advanced adenocarcinoma of the colon and rectum.

\section{Materials and methods}

Forty-two patients were registered from eight institutions. VM-26 was given at $60 \mathrm{mg} / \mathrm{M}^{2} \mathrm{IV}$ infusion over $1 / 2$ hour daily for 5 days every 28 days. Patients were eligible if the serum creatinine was $\leq 2.0$ $\mathrm{mg} / \mathrm{dl}$, serum bilirubin $<2.0 \mathrm{mg} / \mathrm{dl}$, and performance status $\leq 2$. Dose adjustment for subsequent courses was allowable depending on nadir counts.
No patients had received previous chemotherapy. Eleven patients previously received radiation therapy, all of them to the pelvis, but four weeks had elapsed before VM-26 was started. Male to female ratio was $3: 2$ with a median age of 62.5 years (range $24-80$ years). The SWOG performance status was 0 for 20 patients, 1 for 19 , and 2 for 3 patients. Response and toxicity were determined according to SWOG criteria.

\section{Results}

All registered patients were eligible, although response could not be evaluated in six patients due to toxicity or early refusal of additional therapy. Response was seen in 2 of the 42 eligible patients $(5 \% ; 95 \%$ confidence interval, $0.6 \%-16.2 \%)$. One patient with an intrahepatic lesion had a complete response after the third course. In addition, his CEA decreased from $9 \mathrm{ng} / \mathrm{ml}$ to $0.7 \mathrm{ng} / \mathrm{ml}$. His complete response lasted for 6 months and he survived 18 months. One patient had a partial response 
with greater than $50 \%$ decrease in the size of lesions in his right supraclavicular node and liver. This occurred after two courses. His CEA decreased from $15.2 \mathrm{ng} / \mathrm{ml}$ to $4.6 \mathrm{ng} / \mathrm{ml}$. This patient relapsed after 4 months and survived 11 months. Ten other patients $(24 \%)$ had a period of stable disease. Thirteen patients were placed on 5-FU and folinic acid at the time of progression (L. Laufman, personal communication). Three patients were reported to have a complete response lasting 10, 11, and 15 months. Median duration of survival for all 42 patients was 9.4 months.

All 42 patients were evaluable for toxicity (Table 1). There were no drug related deaths. Severe to life-threatening leukopenia was the most frequent toxicity seen in $17(40 \%)$ patients. Alopecia was a finding not seen with weekly doses of VM-26 [3] but moderate to severe alopecia occurred in $15(30 \%)$ patients. Two patients had life-threatening anaphylaxis. One patient developed severe shortness of breath, flushing, and hypertension after receiving $20 \mathrm{mg}$ VM-26. This patient's infusion was discontinued and the patient was given benadryl. The second patient felt hot and swollen with chest and back pain after 1-2 minute infusion. This patient was hospitalized and given hydrocortisone. This reaction was felt to be caused by the vegetable oil base used in the preparation of VM-26. One patient had blurring of vision so that therapy was discontinued. One patient refused further therapy after his first course. No reason was given. This patient had shown a $25 \%$ decrease in the abdominal lesion and supraclavicular nodes. Mild hypotension and flushing occurred in three patients who continued treatment without further adverse reactions.

\section{Discussion}

Locker et al. $[4,5]$ treated 72 patients with advanced colorectal carcinoma with VM-26 at $100 \mathrm{mg} / \mathrm{M}^{2} \mathrm{IV}$ weekly. Eighteen patients had no prior chemotherapy or radiotherapy. There were no objective responses seen in 66 evaluable patients. Thirty patients with stable disease of two months or longer, survived longer than the overall survival. In other phase II trials with VM-26 in colorectal carcinoma, two of 20 patients responded [6-8].
Table 1. Severe or life-threatening toxicity in 42 patients

\begin{tabular}{lc}
\hline Anaphylaxis & $2(5 \%)$ \\
Anemia & $3(7 \%)$ \\
CNS & $1(2 \%)$ \\
Leukopenia & $17(40 \%)$ \\
Nausea and Vomiting & $2(5 \%)$ \\
Thrombocytopenia & $2(5 \%)$ \\
\hline
\end{tabular}

In this SWOG study, one complete response and one partial response were seen in 42 patients suggesting minimal activity in patients with colorectal cancer.

\section{Acknowledgements}

This investigation was supported in part by the following PHS Cooperative Agreement grant numbers awarded by the National Cancer Institute, DHHS: CA-32734, CA-37429, CA-35261, CA35090, CA-27057, CA-35192, CA-12213, CA28862, CA-13238, CA-32102.

\section{References}

1. Wampler GL, Schultz JJ, Mueller JM, Speckhart J, Taub RN: Pilot Study of 5-Fluorouracil + Teniposide in Treatment of Advanced Colorectal Carcinoma. (Abstr) Proc Amer Soc Clin Oncol 22:452, 1981

2. Woods RL, Fox RM, Tattersall MHN: Treatment of Small Cell Carcinoma with VM-26. Cancer Treat Rep 63:20112013, 1979

3. Oishi N, Berenberg I, Blumenstein BA, Johnson K, Rivkin SE, Bukowski RM, O'Bryan RM, Stephens RL, Quagliana J, Saiers JH, Crawford ED: Teniposide in Metastatic Renal and Bladder Cancer: A Southwest Oncology Group Study. Cancer Treat Rep 71(12):1307-1308, 1987

4. Locker GY, Lanzotti V, Khandekar JD: Phase II Trial of Teniposide in Previously Treated and Untreated Patients with Advanced Colorectal Carcinoma: An Illinois Cancer Council Trial. Cancer Treat Rep 70(2):307-308, 1986

5. Locker GY, Lanzotti V, Khandekar J, Sweet D, Shaw J, Krauss S, Chernicoff D, Bitran J, Stiff P, Miller S, Johnson C: VM-26 in Advanced Adenocarcinoma of the Colon and Rectum: An Illinois Cancer Council Phase II Study. (Abstr) Proc Amer Soc Clin Oncol 3:134, 1984

6. O’Dwyer PJ, Alonso MT, Leyland-Jones B, Marsoni S: Teniposide: A Review of 12 Years of Experience. Cancer Treat Rep 68:1455-1464, 1984 
7. Dombernowsky P, Nissen NI, Larsen V: Clinical Investigation of a New Podophyllum Derivative, Epipodophyllotoxin, 4 ' -Demethyl-9-(4,6-O-2-thenylidene- $\beta$-D-glucopyranoside) (NSC-122819), in Patients with Malignant Lymphomas and Solid Tumors. Cancer Chemother Rep 56:71-82, 1972

8. Spremulli E, Schulz JJ, Speckhart VJ, Wampler GL: Phase
II Study of VM-26 in Adult Malignancies. Cancer Treat Rep $64: 147-149,1980$

Address for offprints: Southwest Oncology Group (SWOG 8426), Operations Office, 5430 Fredericksburg Road, Suite \#618, San Antonio, TX 78229, USA 